\title{
Immunohistochemical analysis of lattice corneal dystrophies types I and II
}

\author{
Tero Kivelä, Ahti Tarkkanen, Ian McLean, Jorge Ghiso, Blas Frangione, Matti Haltia
}

\begin{abstract}
Corneal buttons from four patients with lattice corneal dystrophy (LD) type I, thought to be an isolated corneal amyloidosis, and from six patients with LD type II, part of systemic familial amyloidosis, Finnish type (FAF; Meretoja's syndrome), were studied by immunohistochemistry to determine the differential distribution in the amyloid deposits of amyloid $P$ component (AP), mutated gelsolin specific for FAF, and native gelsolin. In both types of LD, antibodies to AP labelled lattice lines and a discontinuous layer of amyloid deposits under Bowman's layer. In LD type II, particularly, they also reacted with streak-like amyloid deposits between corneal almellae, especially in the limbal region. While the antiFAF antiserum strongly labelled all amyloid deposits in LD type II, it failed to react unequivocally with them in LD type I. Both in LD type I and in two control specimens representing granular dystrophy, the monoclonal antibody (MAb) GS-2C4 to gelsolin faintly labelled some deposits, while in LD type II it reacted non-homogeneously with most amyloid deposits. In all specimens, MAb GS-2C4 labelled corneal epithelial cells and occasional stromal keratocytes and endothelial cells. The results suggest that Meretoja's syndrome, a systemic disease, can be diagnosed even retrospectively from corneal buttons subjected to histopathological study.

(Br f Ophthalmol 1993; 77: 799-804)
\end{abstract}

Lattice corneal dystrophies (LD) are hereditary diseases characterised by lace-like deposition of amyloid within the corneal stroma. ${ }^{12}$ Three clinically and histopathologically distinct types of LD have been reported. ${ }^{3-6}$ Types I and II are inherited as an autosomal dominant and type III as an autosomal recessive trait. ${ }^{1-57}$ Only LD type II is known to be associated with systemic amyloidosis, namely familial amyloidosis, Finnish type (FAF), also called Meretoja's syndrome. ${ }^{48}$ LD is usually the earliest clinical finding in FAF ${ }^{47-9}$ Slowly progressive cranial and peripheral neuropathy, dry and itchy skin and eyes, dermatochalasis, depressed eyebrows, protruding lips, and intermittent proteinuria develop later. ${ }^{471011}$ Although it is most common in south eastern Finland, ${ }^{47}$ families have been encountered elsewhere in Europe and the United States. ${ }^{12-19}$

Recently the genetic defect underlying FAF has been unravelled. ${ }^{18-32}$ The amyloid fibrils correspond to a $7 \mathrm{kDa}$ internal degradation product of human gelsolin, a widely dispersed, calcium dependent, regulatory cytoplasmic and plasma protein involved in actin severing and gel sol transformation..$^{20-26}$ It spans position 173 to 243 in the native protein, with asparagine 187 substituted for aspartic acid. ${ }^{20-26}$ This results from a single guanine to adenine transition at position 654 , the first nucleotide of codon 187 , within a highly conserved, repetitive motif of the gelsolin gene. ${ }^{27}{ }^{28}$ FAF cosegregates with this mutation, it is particularly severe in those homozygously affected, and the mutation has been shared by all Finnish and American patients examined. 11819 27-31 Aberrant degradation of mutated gelsolin probably causes the amyloid deposition, as such peptides have a tendency to form amyloid fibres in vitro. ${ }^{32}$

This report analyses the presence of native and mutated gelsolin in LD types I and II with Congo red and amyloid $\mathbf{P}$ component staining to determine whether the two types can be differentiated from each other by immunohistochemical methods.

\section{Material and methods}

\section{HISTOLOGICAL SPECIMENS}

Corneal buttons obtained at the time of penetrating keratoplasty from two Finnish patients with LD type I and three patients with LD type II were taken from the files of the ophthalmic pathology laboratory, Helsinki University Central Hospital, and three buttons from two American patients with LD type I from the department of ophthalmic pathology, Armed Forces Institute of Pathology (Table 1). Four eyes from three Finnish patients with LD type II were obtained at autopsy from the department of pathology, University of Helsinki.

All six patients with LD type II had typical clinical findings of familial amyloidosis, Finnish type (FAF), and a positive family history of the disease, and they came from the Kymenlaakso region in south eastern Finland, known to have a high prevalence of Meretoja's syndrome. ${ }^{47}$ In the four patients with LD type I, the disease appeared to be an isolated phenomenon unrelated to symptoms of systemic amyloidosis. For control purposes, identically processed corneal buttons from patients with granular dystrophy (ages 38 and 43 years), keratoconus (ages 27,44 , and 50 years), and leucoma (ages 78 and 81 years) were selected.

All specimens were formalin fixed and paraffin embedded. Routine stains included haematoxylin and eosin, van Gieson, Congo red, Masson trichrome, and periodic acid Schiff. Criteria for identifying an amyloid deposit were birefringence and apple green dichroism observed under polarised optics after Congo red staining. 
Table 1 Immunoreactivity of dystrophic deposits in corneal lattice and granular dystrophies with antibodies to amyloid $P$ component, mutated gelsolin, and native human gelsolin

\begin{tabular}{|c|c|c|c|c|c|c|c|}
\hline Case & Sex & $\begin{array}{l}\text { Age } \\
\text { (years) }\end{array}$ & Diagnosis & Nationality & anti-AP $P^{a}$ & $a n t i-F A F^{a}$ & $G S-2 C 4^{a}$ \\
\hline $\begin{array}{l}\text { Lla } \\
\text { L1b } \\
\text { L2 } \\
\text { L3 } \\
\text { L4 }\end{array}$ & $\begin{array}{l}\text { Male }^{\mathrm{b}} \\
\text { Male }^{\mathrm{b}} \\
\text { Female } \\
\text { Female } \\
\text { Male }\end{array}$ & $\begin{array}{l}21 \\
22 \\
24 \\
55 \\
75\end{array}$ & $\begin{array}{l}\text { Lattice dystrophy, type I } \\
\text { Lattice dystrophy, type I } \\
\text { Lattice dystrophy, type I } \\
\text { Lattice dystrophy, type I } \\
\text { Lattice dystrophy, type I }\end{array}$ & $\begin{array}{l}\text { American } \\
\text { American } \\
\text { American } \\
\text { Finnish } \\
\text { Finnish }\end{array}$ & $\begin{array}{l}++ \\
+ \\
++ \\
+ \\
++\end{array}$ & $\begin{array}{l}(+)^{c} \\
(+)^{c} \\
(+)^{c} \\
- \\
-\end{array}$ & $\begin{array}{l}\text { NA } \\
\text { NA } \\
- \\
(+)^{c} \\
(+)^{c}\end{array}$ \\
\hline $\begin{array}{l}\text { M1 } \\
\text { M2 } \\
\text { M3 } \\
\text { M4 } \\
\text { M5 } \\
\text { M6 }\end{array}$ & $\begin{array}{l}\text { Female } \\
\text { Female } \\
\text { Male } \\
\text { Male } \\
\text { Female } \\
\text { Female }\end{array}$ & $\begin{array}{l}65 \\
66 \\
72 \\
72 \\
78 \\
80\end{array}$ & $\begin{array}{l}\text { Lattice dystrophy, type II } \\
\text { Lattice dystrophy, type II } \\
\text { Lattice dystrophy, type II } \\
\text { Lattice dystrophy, type II } \\
\text { Lattice dystrophy, type II } \\
\text { Lattice dystrophy, type II }\end{array}$ & $\begin{array}{l}\text { Finnish } \\
\text { Finnish } \\
\text { Finnish } \\
\text { Finnish } \\
\text { Finnish } \\
\text { Finnish }\end{array}$ & $\begin{array}{l}++ \\
+ \\
++ \\
+ \\
+ \\
++\end{array}$ & $\begin{array}{l}++ \\
++ \\
++ \\
++ \\
++ \\
++\end{array}$ & $\begin{array}{l}+ \\
+ \\
+ \\
+ \\
+ \\
+\end{array}$ \\
\hline $\begin{array}{l}\mathrm{Cl} \\
\mathrm{C} 2\end{array}$ & $\begin{array}{l}\text { Female } \\
\text { Female }\end{array}$ & $\begin{array}{l}38 \\
43\end{array}$ & $\begin{array}{l}\text { Granular dystrophy } \\
\text { Granular dystrophy }\end{array}$ & $\begin{array}{l}\text { Finnish } \\
\text { Finnish }\end{array}$ & - & - & $\begin{array}{l}-1+c \\
-1+c\end{array}$ \\
\hline
\end{tabular}

-AP amyloid $\mathrm{P}$ component; FAF =mutated variant gelsolin; $\mathrm{GS}=$ native gelsolin; $++=$ strong; $+=$ moderate; $(+)=$ weak

immunoreaction; NA=not applicable.

${ }^{b}$ Both specimens from the same patient.

'Focal reaction mainly in the periphery of the deposits.

'Autopsy material.

- Keratoconus in addition to lattice dystrophy.

\section{IMMUNOHISTOCHEMISTRY}

Immunoperoxidase staining was carried out using commercial versions (Vectastain ABC Elite Kits for rabbit and mouse IgG; Vector Laboratories, Burlingame, CA, USA) of the avidin biotinylated peroxidase complex (ABC) method as has been described in detail. ${ }^{33}$

A rabbit antiserum was raised against purified amyloid subunit obtained by gel filtration of amyloid fibrils isolated from kidneys of a patient suffering from FAF. ${ }^{21-23}$ This fraction is homologous to that of human gelsolin, starting at position 173, but it shows an amino acid substitution, asparagine for aspartic acid, at position 187. ${ }^{22}$ On immunoblot analysis, the antiserum reacts strongly with the FAF amyloid subunit and weakly with normal gelsolin. ${ }^{22}$ It labels amyloid deposits in renal glomeruli, conjunctiva, skin, eccrine sweat glands, perineurial sheaths, and blood vessel walls in FAF, but does not label these tissues in controls. ${ }^{21-23}$ Absorption with purified FAF amyloid subunit abolishes the immunoreaction. ${ }^{21} 23$ Cross reactivity has not been detected in several other types of amyloidosis. ${ }^{23}$ The optimal dilution in this study was 1:800.

Mouse monoclonal antibodies to human gelsolin (GS-2C4, IgG 1 , Lot 041H-4847; dilution 1:750) were obtained from Sigma (St Louis, MO, USA). It detects an epitope on a $47 \mathrm{kDa}$ chymotryptic cleavage peptide corresponding to residues $407-755$ of the $93 \mathrm{kDa}$ plasma gelsolin and containing its carboxy terminal actin binding site. ${ }^{34}$ It does not react with the FAF amyloid protein, derived from the amino terminal end of gelsolin.22 A rabbit antiserum to human amyloid P component (A302, Lot 118; dilution 1:500) was purchased from Dakopatts (Glostrup, Denmark).

\section{CONTROL EXPERIMENTS}

Omitting the primary or secondary antibody or the ABC complex abolished the immunoreaction. Normal rabbit serum (Ortho Diagnostics, Stillwater, MN, USA) and an unrelated murine $\mathrm{IgG}_{1}$ antibody (anti-synaptophysin, SY 38; Boehringer Mannheim, Mannheim, Germany) were used as negative controls. Purified amyloid protein was no longer available for blocking.

\section{Results}

\section{LD TYPE I}

By light microscopy, three specimens represented moderately advanced dystrophy (Fig 1A-D) with relatively scarce lattice lines within the corneal stroma in Congo red staining (Fig 1A), and two came from patients with advanced lattice dystrophy (Fig $1 \mathrm{E}-\mathrm{H}$ ) displaying many lattice lines of various sizes throughout the stroma (Fig 1E, F). A discontinuous layer of amyloid was present under Bowman's layer (Fig 1A), partly replacing it in the two advanced cases (Fig 1E, F).

The anti-AP antiserum labelled diffusely lattice lines in all specimens studied (Fig 1B, G; Table 1). In four cases, it also reacted focally with amyloid deposits associated with Bowman's layer (Fig 1B, G). The epithelial basement membrane was not labelled. The anti-FAF antiserum could label weakly the cytoplasm of corneal epithelial and endothelial cells, consistent with its weak cross reactivity with native gelsolin (Fig $1 \mathrm{C}, \mathrm{H}$ ). In two specimens, scattered stromal keratocytes were also labelled (Fig 1H). Amyloid deposits around Bowman's layer remained negative (Fig $1 \mathrm{C}, \mathrm{H})$. In two specimens, lattice lines were negative, but in three others the antiserum faintly bound to their periphery $(\mathrm{Fig} 1 \mathrm{C}, \mathrm{H})$. For technical reasons, two specimens remained totally negative with MAb GS-2C4 and could not be evaluated. It labelled the cytoplasm of corneal epithelial cells and endothelial cells, and a subpopulation of stromal keratocytes in the remaining specimens. It two of these specimens, focal immunoreaction was seen in the periphery of some lattice lines (Fig 1D).

\section{LD TYPE II}

By light microscopy, all six specimens contained relatively few and thin lattice lines (Fig 2A-E), which concentrated to the anterior and middle stroma. They were seen with equal frequency in the central and peripheral cornea. A variably thick, almost continuous deposition of amyloid was always present under Bowman's layer, and a thin line of amyloid was seen at the level of the epithelial basement membrane in some specimens (Fig 2A, B). Bowman's layer was often 
discontinuous, and scar tissue with occasional amyloid deposits invaded the subepithelial space. Thin amyloid streaks were also seen between superficial corneal lamellae, particularly in the limbal region (Fig 2F).

The anti-AP antiserum labelled lattice lines, amyloid deposits under Bowman's layer, and amyloid streaks between corneal lamellae with a weak to moderate intensity (Fig 2C, G; Table 1). Immunoreaction was also seen focally at the level of epithelial basement membrane (Fig 2C) and in amyloid deposits invading the subepithelial scar tissue. The anti-FAF antiserum strongly and consistently labelled lattice lines and amyloid deposits around Bowman's layer (Fig 2D). This immunoreaction was most extensive under the Bowman's layer, but was also often seen at the level of the epithelial basement membrane (Fig 2D), and could involve the entire Bowman's layer. Immunopositive streaks between corneal lamellae were seen especially near the limbal region (Fig 2H). MAb GS-2C4 gave a faint to moderate, non-homogeneous granular immunoreaction in many lattice lines, amyloid deposits under Bowman's layer, and in streaks of amyloid between corneal lamellae (Fig 2I). Other deposits


ep

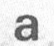

\section{a}


Figure 1 Immunohistochemistry of lattice corneal dystrophy type $I(A, E, F$ Congo red; $B-D, G, H$ immunoperoxidase staining). In moderately advanced dystrophy $(A-D$, case $L 3)$ Congo red $(A ; \times 225)$ and antiserum to amyloid $P$ component $(A P)(B ; \times 250)$ reveal amyloid in lattice lines $(a)$ and as discontinuous deposits (arrowhead) under Bowman's layer $(b)$, whereas the cormeal epithelium (ep) remains unreactive. The anti-FAF antiserum binds to desquamating corneal epithelial cells and labels faintly other epithelial $(e p)$ layers, but lattice lines $(a)$ and amyloid (arrowhead) under Bowman's layer (b) do not react with it $(C ; \times 250)$. MAb GS-2C4 to gelsolin reacts strongly with the corneal epithelium $(e p)$ and in a focal pattern with lattice lines (a), but it is not immunoreactive with amyloid deposits (atrowhead) under Bowman's layer $(b)(D ; \times 250)$. Advanced lattice dystrophy $(E-H$, case L1b) with abundant lattice lines (a), extending up to the endothelium (double arrowhead), and anterior deposits totally replacing Bowman's layer (arrowhead) are seen in Congo red stainings without $(E ; \times 185)$ and with polarisation $(F ; \times 185)$, as well as with the antiserum to $A P(G ; \times 260)$. In addition to faint epithelial labelling $(e p)$, the antiserum to FAF reacts with the periphery of lattice lines (a) and with single stromal keratocytes (double arrowhead), but it does not label amyloid deposits (arrowhead) under Bowman's layer or the core of lattice lines $(H ; \times 330)$. 
remained totally negative, however (Fig $2 \mathrm{E}$ ). As in other specimens, it labelled the cytoplasm of corneal epithelial cells, along with scattered keratocytes, preferably in the anterior and middle stromal layers (Fig 2E).

CONTROL MATERIAL

The amyloid deposits in LD types I and II did not react with normal rabbit serum or the control $\mathrm{MAb}$ of $\mathrm{IgG}_{1}$ isotype. Amyloid was not found in any control specimen with Congo red or the antiAP antiserum (Fig 3A, B). The anti-FAF antiserum labelled single desquamating corneal epithelial cells and, in a few specimens, scattered keratocytes, similar to those in some specimens of lattice dystrophy (Fig 1C, H). It faintly bound to the periphery of several deposits in granular dystrophy, resembling edge artefact (Fig 3C; Table 1). A strong reaction in many subepithelial deposits of granular dystrophy was seen with MAb GS-2C4 to gelsolin (Fig 3D). Otherwise, it bound to the corneal epithelium, endothelium, and scattered keratocytes.

\section{Discussion}

Traditionally, the lattice lines in LD type I tend
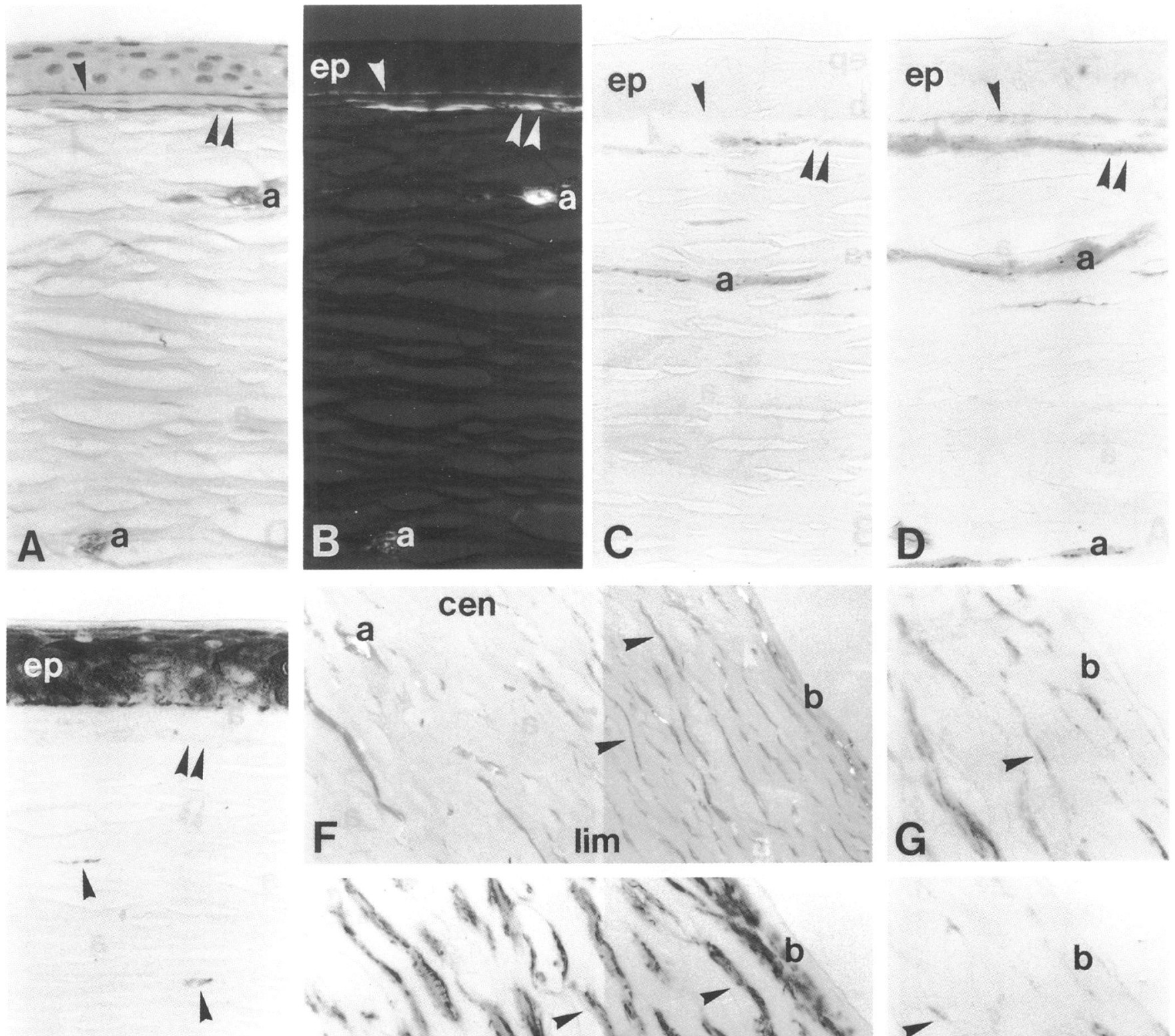

E
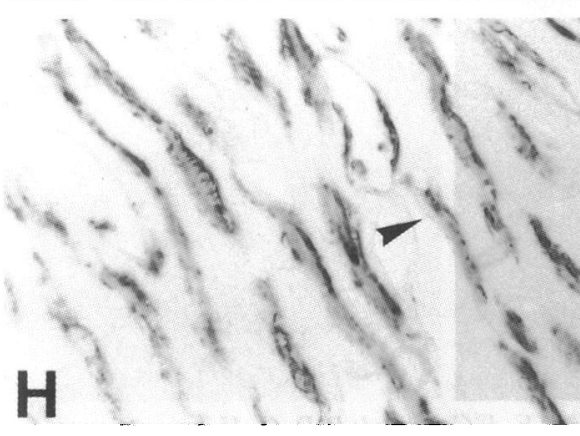

Figure 2 Immunohistochemistry of lattice corneal dystrophy type II $(A, B, F$ Congo red; $C-E, G-I$ immunoperoxidase staining). Congo red staining (A-E, case M6) without $(A ; \times 240)$ and with $(B ; \times 240)$ polarisation reveals a thin layer of amyloid (double arrowhead) under Bowman's layer, and stromal lattice lines $(a)$. The epithelial (ep) basement membrane (arrowhead) is also labelled. Antisera to amyloid $P$ component $(A P)(C ; \times 300)$ and $F A F(D ; \times 300)$ react with lattice lines $(a)$, anterior stromal amyloid deposits (double arrowhead), and occasional streaks of amyloid between stromal lamellae, whereas only the latter labels the epithelial basement membrane (arrowhead). MAb GS-2C4 to gelsolin reacts with the cytoplasm of corneal epithelial cells (ep) and occasional stromal keratocytes (arrowheads), but in this specimen does not label the anterior stromal deposits (double arrowhead) or streaks between corneal lamellae $(E ; \times 300)$. In peripheral cornea (F-I, case M5), abundant thin amyloid deposits (arrowheads) are observed between cormeal lamellae, more so towards the limbus (lim) than the centre $(c e n)$ of the cormea $(F ; \times 130)$. Amyloid deposits under Bowman's layer $(b)$ are also seen. The amyloid streaks (arrowheads) react moderately for $A P(G ; \times 300)$, strongly for $F A F(H ; \times 300)$, and weakly for gelsolin $(I ; \times 300)$. The epithelium has detached from this autopsy specimen. 
to be more numerous and thinner, they extend more deeply into the corneal stroma, and spare more of its periphery than do those in LD type II. ${ }^{29}$ The former becomes symptomatic earlier and progresses more rapidly than the latter, which rarely requires corneal transplantation, even though it becomes manifest by the age of $20 .^{47-9}$ The clinical clue to LD type II is the typical facies with droopy eyelids and protruding lips, due to cutaneous and cranial nerve involvement by amyloid deposits. ${ }^{41012-16}$

In LD type II, an even layer of amyloid is seen at the level of the epithelial basement membrane and beneath Bowman's layer, which may show breaks in continuity, and stromal lattice lines are thin. ${ }^{89}{ }^{17} \mathrm{We}$ are aware of only one previous paper that has specifically compared the histopathology of LD types I and II. ${ }^{9}$ It noted more frequent and coarse amyloid deposition between the epithelium and fragmented Bowman's layer, thicker and more irregular amyloid deposits under Bowman's layer, and more widespread distribution of lattice lines in LD type I. ${ }^{9}$ These general findings were confirmed in our material. Moreover, thin streaks of amyloid between corneal lamellae were noted in LD type II, particularly in the limbal region, possibly associated with stromal keratocytes, a feature not emphasised before.

The antiserum to the variant gelsolin amyloid subunit of a patient with Meretoja's syndrome always labelled lattice lines, as well as amyloid deposits on both sides of Bowman's layer and between corneal lamellae in LD type II, in line with preliminary observations in one American and three Finnish patients with FAF. ${ }^{1823}$ Immunoblotting has shown that the mutated gelsolin polypeptide is indeed present in the affected cornea. ${ }^{18} \mathrm{MAb}$ GS-2C4 to native human gelsolin $^{34}$ reacted focally with corneal amyloid deposits in LD type II, consistent with the fact that, in many types of amyloidosis, variable amounts of the precursor protein can be deposited along with the amyloid polypeptide. Indeed, in some patients with FAF at least, the normal allele may be coexpressed with the mutated one. ${ }^{22}$ Since $\mathrm{MAb}$ GS-2C4 recognises a carboxy terminal epitope of gelsolin, ${ }^{34}$ absent from the FAF amyloid fragment derived from its amino terminal end, it is not a very useful reagent for demonstration of LD type II. Identical reactivity has nevertheless been reported in two previously studied specimens. ${ }^{2335}$

Convincing labelling of amyloid deposits was not obtained with the anti-FAF antiserum in LD type I. MAb GS-2C4 to gelsolin was initially reported to be non-reactive with LD type I and other corneal amyloidoses..$^{18}$ More.recently, a moderate to intense immunoreaction, mainly bordering lattice lines, was reported in four of six corneal buttons in LD type I. ${ }^{35}$ Similar immunoreaction was occasionally seen in polymorphic amyloid degeneration, primary familial subepithelial amyloidosis, and secondary corneal amyloidosis, and it was speculated to result from changes in molecular conformation of presumed abnormal gelsolin fragments in the centre of these deposits. ${ }^{35}$ In the present study, not only two of three evaluable specimens of LD type I, but also both cases of granular dystrophy reacted focally with MAb GS-2C4, suggesting that plasma gelsolin may bind to several types of corneal deposit. Thus, the significance of focal binding of MAb GS-2C4 to amyloid deposits other than LD type II remains open to discussion.

These results are insufficient to prove that LD type $\mathrm{I}$ is unrelated to gelsolin, as it might result from another mutation in the gelsolin gene or a different degradation pathway of the amyloid precursor. They are, nevertheless, consistent with a recent linkage analysis in a large kindred, which seemed to exclude gelsolin as a candidate gene for LD type $I$ in this particular family. ${ }^{36}$ Failure to label the amyloid deposits with anti-

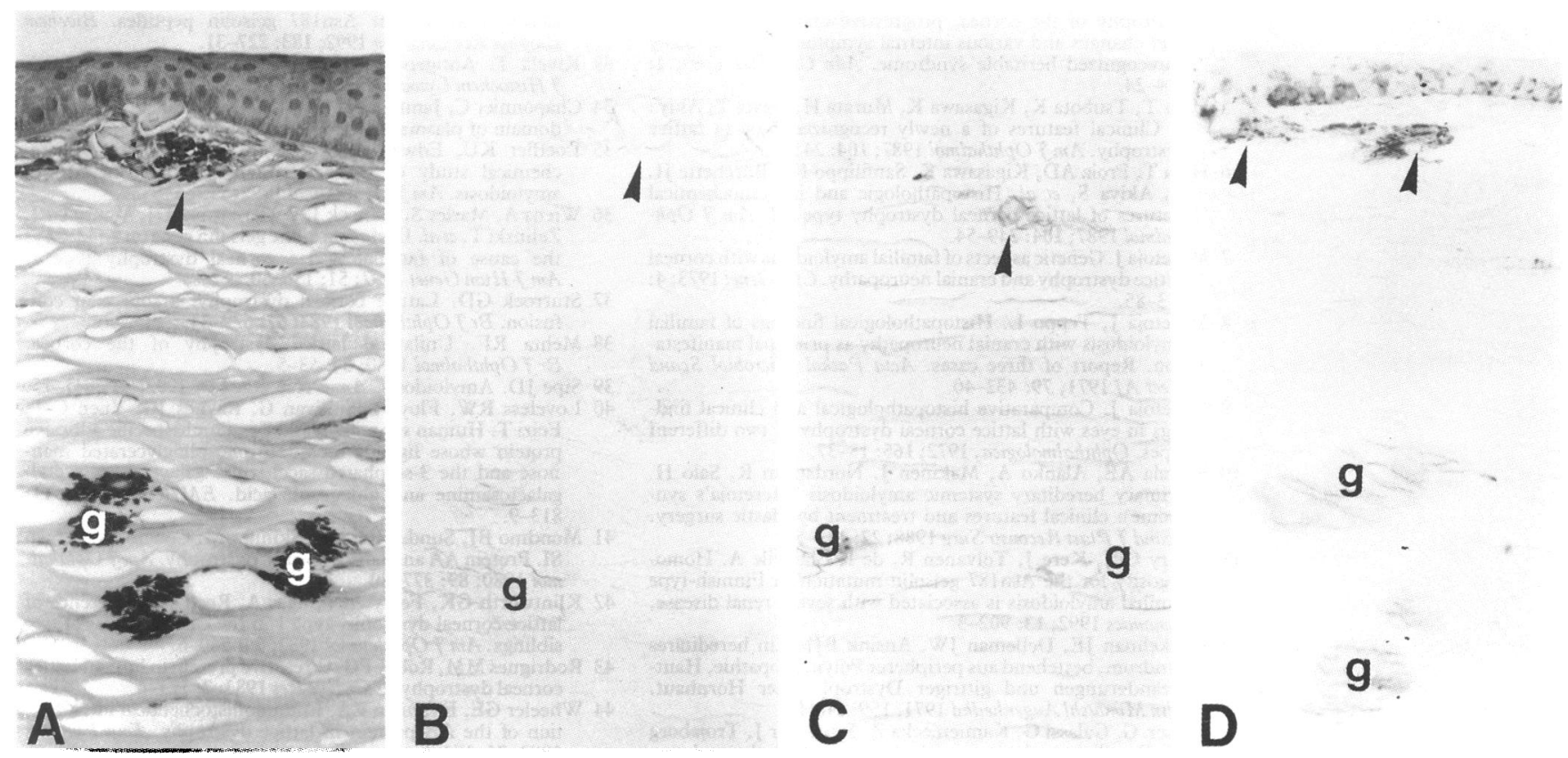

Figure 3 Immunohistochemistry of control specimens with granular dystrophy (A Masson trichrome; $B$-D immunoperoxidase staining). Light microscopy (A$D$, case C2) reveals dystrophic deposits both deep within the stroma (g) and subepithelially (arrowhead) $(A ; \times 150)$. Neither anterior (arrowhead) nor deep deposits $(g)$ react reliably with the anti-amyloid $P$ component $(B ; \times 150)$ and anti-FAF antiserum $(C ; \times 300)$, respectively, giving edge artefact-like reaction, but $M A B$ GS-2C4 to gelsolin labels quite strongly the subepithelial deposits (arrowheads) $(D ; \times 150)$. 
bodies to gelsolin was reported in this kindred. ${ }^{36}$ However, because LD type I is quite a heterogeneous disease as to its clinical presentation, age of onset, laterality, and degree of stromal involvement, ${ }^{12378}$ it is not yet certain that the precursor protein is identical in all families.

Finally, amyloid deposits in LD type I and II reacted for amyloid $\mathrm{P}$ component (AP), a plasma protein probably deposited along with the amyloidogenic protein in all types of amyloidosis. ${ }^{39} 40$ Whereas most, but not all, previous studies have confirmed its presence in LD types $\mathrm{II}^{15-172123}$ and III, ${ }^{6}$ highly conflicting results have been reported for LD type $I .{ }^{41-45}$ The presence of $A P$ in all types of $L D$ is perhaps to be expected, and it cannot be used to differentiate between them.

Although molecular genetic studies are likely to become the most reliable means of differentiating between various types of lattice dystrophy in the clinical setting, and identifying affected family members before they develop biomicroscopically detectable corneal changes, ${ }^{27} 291$ the anti-FAF antiserum should prove a very useful reagent for rapidly screening corneal specimens to determine whether there is evidence of $\mathrm{LD}$ type II. As the antigen is resistant to formalin fixation and paraffin embedding, retrospective studies of old corneal buttons will be possible. Meretoja's syndrome is a relatively unknown and most probably underdiagnosed condition, and such studies might lead to a better understanding of its world distribution and epidemiology.

This study was financially supported by Suomen Kulttuurirahasto and NIH grant number NS 30455 .

1 Waring GO III, Rodrigues MM, Laibson PR. Corneal dystrophies. I. Dystrophies of the epithelium, Bowman's layer trophies. I. Dystrophies of the epithelium, Bow

2 Miller CA, Krachmer JH. Epithelial and stromal dystrophies In: Kaufman HE, Barron BA, McDonald MB, Waltman SR, eds. The cormea. New York: Churchill Livingstone, 1988: 404-9.

3 Klintworth GK. Lattice corneal dystrophy. An inherited variety of amyloidosis restricted to the cornea. Am $\mathcal{F}$ Pathol 1967; 50: 371-99.

4 Meretoja J. Familial systemic paramyloidosis with lattice dystrophy of the cornea, progressive cranial neuropathy, skin changes and various internal symptoms. A previously unrecognized heritable syndrome. Ann Clin Res 1969; 1 314-24.

5 Hida T, Tsubota K, Kigasawa K, Murata H, Ogata T, Akiya $S$. Clinical features of a newly recognized type of lattice dystrophy. Am f Ophthalmol 1987; 104: 241-8.

6 Hida T, Proia AD, Kigasawa K, Sanfilippo FP, Burchette JL $\mathrm{Jr}$, Akiya S, et al. Histopathologic and immunochemical $\mathrm{Jr}$, Akiya S, et al. Histopathologic and immunochemical features of lattice corneal

7 Meretoja J. Genetic aspects of familial amyloidosis with corneal lattice dystrophy and cranial neuropathy. Clin Genet 1973; 4 173-85

8 Meretoja J, Teppo L. Histopathological findings of familia amyloidosis with cranial neuropathy as principal manifestation. Report of three cases. Acta Pathol Microbiol Scand [Sect A] 1971; 79: 432-40.

9 Meretoja J. Comparative histopathological and clinical findings in eyes with lattice corneal dystrophy of two different types. Ophthalmologica, 1972;165: 15-37.

10 Rintala AE, Alanko A, Mäkinen J, Nordström R, Salo H. Primary hereditary systemic amyloidosis (Meretoja's syndrome): clinical features and treatment by plastic surgery. Scand $\mathcal{F}$ Plast Reconstr Surg 1988; 22: 141-5.

11 Maury CPJ, Kere J, Tolvanen R, de la Chapelle A. Homozygosity for the Asn 187 gelsolin mutation in Finnish-type zygosity for the Asn 187 gelsolin mutation in Finnish-type Genomics 1992; 13: $902-3$.

12 Winkelman JE, Delleman JW, Ansink BJJ. Ein hereditäre Syndrom, bestehend aus peripherer Polyneuropathie, Hautveränderungen und gittriger Dystrophie der Hornhaut. Klin Monatsbl Augenheilkd 1971; 159: 618-23.

13 Boysen G, Galassi G, Kamieniecka Z, Schlaeger J, Trojaborg W. Familial amyloidosis with cranial neuropathy and corneal lattice dystrophy. $\mathcal{F}$ Neurol Neurosurg Psychiatry 1979 42: $1020-30$.

14 Sack GH, Dumars KW, Gummerson KS, Law A, McKusick VA. Three forms of dominant amyloid neuropathy. Fohns Hopkins Med F 1981; 149: 239-47.
15 Purcell JJ Jr, Rodrigues M, Chishti MI, Riner RN, Dooley JM. Lattice corneal dystrophy associated with familial systemic amyloidosis (Meretoja's syndrome). Ophthalmology 1983; 90: 1512-7.

16 Darras BT, Adelman LS, Mora JS, Bodziner RA, Munsat TL. Familial amyloidosis with cranial neuropathy and corneal lattice dystrophy. Neurology 1986; 36: 432-5.

17 Starck T, Kenyon KR, Hanninen LA, Beyer-Machule C, Fabian R, Gorn RA, et al. Clinical and histopathologic studies of two families with lattice corneal dystrophy and familial systemic amyloidosis (Meretoja syndrome) Ophthalmology 1991; 98: 1197-206.

18 Gorevic PD, Munoz PC, Gorgone G, Purcell JJ Jr, Rodrigues M, Ghiso J, et al. Amyloidosis due to a mutation of the gelsolin gene in an American family with lattice cornea dystrophy type II. N Engl F Med 1991; 325: 1780-5.

19 de la Chapelle A, Kere J, Sack GH, Tolvanen R, Maury CPJ Familial amyloidosis, Finnish type: G654 $\rightarrow$ A mutation of the gelsolin gene in Finnish families and an unrelated American family. Genomics 1992; 13: 898-901.

20 Kwiatkowski DJ, Mehl R, Yin HL. Genomic organization and biosynthesis of secreted and cytoplasmic forms of gelsolin. f Cell Biol 1988; 106: 375-84.

21 Haltia M, Prelli F, Ghiso J, Kiuru S, Somer H, Palo J, et al. Amyloid protein in familial amyloidosis (Finnish type) is homologous to gelsolin, an actin-binding protein. Biocher Biophys Res Commun 1990; 167: 927-32.

22 Ghiso J, Haltia M, Prelli F, Novello J, Frangione B. Gelsolin variant (Asn -187) in familial amyloidosis, Finnish type. Biochem $\mathcal{F}$ 1990; 272: 827-30

23 Haltia M, Ghiso J, Prelli F, Gallo G, Kiuru S, Somer H, et al. Amyloid in familial amyloidosis, Finnish type, is antgenically and structurally related to gelsolin. Am F Patho 1990; 136: 1223-7.

24 Maury CPI. Isolation and characterization of cardiac amyloid in familial amyloid polyneuropathy type IV (Finnish): relation of the amyloid protein to variant gelsolin. Biochim Biophys Acta 1990; 1096: 84-6.

25 Maury CPJ, Alli $K$, Baumann $M$. Finnish hereditary amyloidosis. Amino acid sequence homology between the amyloid fibril protein and human plasma gelsolin. FEBS Lett 1990; 260: 85-7.

26 Maury CPJ.Gelsolin-related amyloidosis. Identification of the amyloid protein in Finnish hereditary amyloidosis as fragment of variant gelsolin. $\mathcal{F}$ Clin Invest 1991; 87: 1195-9.

27 Maury CPJ, Kere J, Tolvanen R, de la Chapelle A. Finnish hereditary amyloidosis is caused by a single nucleotide substitution in the gelsolin gene. FEBS Lett 1990; 276: 75-7.

28 Levy E, Haltia M, Fernandez-Madrid I, Koivunen O, Ghiso J, Prelli F, et al. Mutation in gelsolin gene in Finnish hereditary amyloidosis. $\mathcal{F} \operatorname{Exp} M e d 1990 ; 172$ : 1865-7.

29 Hiltunen T, Kiuru S, Hongell V, Heliö T, Palo J, Peltonen L. Finnish type of familial amyloidosis: cosegregation of $\mathrm{ASP}_{187} \rightarrow$ ASN mutation of gelsolin with the disease in three large families. Am 7 Hum Genet 1992; 49: 522-8.

30 Paunio T, Kiuru S, Hongell V, Mustonen E, Syvänen A-C Bengtström $\mathrm{M}$, et al. Solid-phase microsequencing test Bengtstrom $M$, et al. Solid-phase microsequencing tes reveals $A s p_{187} \rightarrow$ Asn $\left(G_{654} \rightarrow A\right)$ mutation of gelsolin in all affected individuals with Finnish

31 Haltia M, Levy E, Meretoja J, Fernandez-Madrid I, Koivunen $O$, Frangione B. Gelsolin gene mutation - at codon 187 - in familial amyloidosis, Finnish: DNA-diagnostic assay. Am ₹ Med Genet 1992; 42: 357-9.

32 Maury CPJ, Nurmiaho-Lassila E-L. Creation of amyloid fibrils from mutant Asn187 gelsolin peptides. Biochem Biophys Res Commun 1992; 183: 227-31.

33 Kivelä T. Antigenic profile of the human lacrimal gland. F Histochem Cytochem 1992; 40: 629-42.

34 Chaponnier $\mathrm{C}$, Janmey $\mathbf{P}$, Yin $\mathbf{H}$. The actin filament-severing domain of plasma gelsolin. $\mathcal{F}$ Cell Biol 1986; 103: 1473-81.

35 Loeffler KU, Edward DP. Tso MOM. An immunohistochemical study of gelsolin immunoreactivity in corneal chemical study of gelsolin immunoreactivity in

36 Wiens A, Marles S, Safneck J, Kwiatkowski DJ, Maury CPJ Zelinski $T$, et al. Exclusion of the gelsolin gene on $9 \mathrm{q} 32-34$ as the cause of familial lattice corneal dystrophy type I. Am F Hum Genet 1992; 51: 156-60.

37 Sturrock GD. Lattice corneal dystrophy: a source of confusion. Br F Ophthalmol 1983; 67: 629-34.

38 Mehta RF. Unilateral lattice dystrophy of the cornea. Br f Ophthalmol 1980; 64: 53-5.

39 Sipe JD. Amyloidosis. Annu Rev Biochem 1992; 61: 947-75.

40 Loveless RW, Floyd-O'Sullivan G, Raynes JG, Yuen C-T, Feizi T. Human serum amyloid $P$ is a multispecific adhesive protein whose ligands include 6-phosphoglycerated mannose and the 3-sulphated saccharides galactose, $N$-acety galactosamine and glucuronic acid. EMBO ff 1992; 11: 813-9.

41 Mondino BJ, Sundar Raj CV, Skinner M, Cohen AS, Brown SI. Protein AA and lattice corneal dystrophy. Am $\mathcal{F}$ Ophthalmol 1980; 89: 377-80.

42 Klintworth GK, Ferry AP, Sugar A, Reed J. Recurrence of lattice corneal dystrophy type 1 in the corneal grafts of two lattice corneal dystrophy type 1 in the corn

43 Rodrigues MM, Robey PG C-reactive protein in human lattice corneal dystrophy. Curr Eye Res 1983; 2: 721-4.

44 Wheeler GE, Eiferman RA. Immunohistochemical identification of the AA protein in lattice dystrophy. Exp Eye Res 1983; 36: 181-6.

45 Gorevic PD, Rodrigues MM, Krachmer JH, Green C Fujihara S, Glenner GG. Lack of evidence for protein AA reactivity in amyloid deposits of lattice corneal dystrophy 98: 216-24. 